\title{
EDITORIAL
}

\section{La falacia del "emptio spei” en Radiología}

Durante los años que estudiamos Medicina nos enseñaron que la relación que estableciéramos con nuestros pacientes sería uno de los pilares fundamentales de nuestra práctica diaria. Sabemos desde entonces, que la relación clásica entre médico y paciente implica que la responsabilidad del médico es cuidar del paciente con las limitaciones impuestas por el avance de la ciencia médica y por la presencia de factores que se pueden escapar al cálculo más riguroso o a las previsiones más prudentes. De esta forma el médico está obligado a asistir a su paciente, a pesar de lo cual, no es posible garantizar que el paciente se cure.

Este contrato entre el médico y el paciente, señala más bien que los médicos tienen para con sus pacientes una "obligación de medios" y no de "resultados", ya que no es posible garantizar un resultado específico en cada caso. En este enfoque, las obligaciones de los medios implican el cumplimiento de la actividad médica utilizando todos los recursos que sus conocimientos, habilidades y destrezas para alcanzar el bienestar del paciente, por sobre cualquier interés. Implica además mantener actualizados los conocimientos y desarrollar capacidades y crecer en experiencia, como el primer imperativo ético de la profesión médica. Y, por cierto, este actuar profesional debe ser enriquecido con virtudes como la compasión, la benevolencia, el respeto a la autonomía del paciente y la sinceridad. El término lex artis del latín significa" ley del arte", o regla de la técnica de la actuación profesional. Esta actuación se debe entonces adecuar a las reglas técnicas pertinentes, lo que permite hablar de un buen profesional y de una buena praxis en el ejercicio de la profesión.

La medicina entonces, entendida como una ciencia que no es exacta, acepta que no siempre se pueda asegurar un resultado favorable. El organismo humano, como un sistema dinámico, luego de la intervención médica, sólo permite aproximarse al resultado, entendiendo que existirán variables incontrolables, por lo que no será posible predecir siempre el resultado final. Si el resultado no se logra, pero el médico ha puesto todo de su parte, no hay responsabilidad de parte suya. Si consideramos que una de las múltiples variables que pueden condicionar el resultado de la intervención médico está condicionado por el azar, nos encontramos frente a lo que el derecho romano llamaba emptio spei o "compra de esperanza". El paciente en este caso acude al médico con la esperanza de sanar y limita su responsabilidad a la diligencia, pericia y prudencia de su accionar médico.

Sin embargo, en la historia de la Medicina, se han ido modelando especialidades cuya finalidad no es la curación del paciente, sino que son el medio para lograr esta finalidad ayudando como medio diagnóstico. En este escenario, la naturaleza de la relación médico-paciente cambia en un supuesto que sí genera una obligación de resultados. Bajo este enfoque, existen ahora en la medicina obligaciones de resultados, descritas para disciplinas como Cirugía Plástica, Laboratorio Clínico, Anatomía Patológica, Medicina Nuclear y Radiología.

Si bien sabemos que por regla general ser médico obliga a emplear los medios técnicos correctos en el ejercicio de la especialidad médica, existirán ahora excepciones donde se compromete el logro de un resultado final esperado por el paciente. Así entonces, los pacientes esperan resultados tan precisos y confiables para la determinación de grupo sanguíneo y una biopsia, como de un DMSA por infección urinaria o una ecotomografía por sospecha de litiasis biliar. Este tipo de contrato se caracteriza porque el cumplimiento exige la obtención de un resultado concreto, no siendo suficiente la realización de las actividades encaminadas a conseguirlo.

Marcelo Gálvez Moya

Editor Científico

Revista Chilena de Radiología 